\title{
Profound hyponatremia in cirrhosis: a case report
}

\author{
Aaron Lindsay
}

\begin{abstract}
Introduction

Cirrhosis of the liver commonly leads to a state of chronic hypervolemic hyponatremia. Profound exacerbation of the hyponatremic state may occur in patients with decompensated cirrhosis in conjunction with acute stressors such as infection or binge alcohol ingestion.

\section{Case presentation}

A 47 year old man with a history of alcoholic cirrhosis presented to the hospital with symptomatic profound hyponatremia (serum sodium concentration of $105 \mathrm{meq} / \mathrm{L}$ ) due to a recent infection and binge drinking. The patient was treated with antibiotics, diuretics and hypertonic saline and was placed on a fluid restricted diet. The serum sodium level corrected slowly over four days with symptomatic improvement occurring after two days. A brief discussion of the symptoms and treatment of acute and chronic hyponatremia in the setting of cirrhosis is included.

\section{Conclusion}

In patients with cirrhosis, it is important to recognize the symptoms of hyponatremia, identify and treat any exacerbating conditions early in their course, and correct the serum sodium concentration slowly with frequent monitoring.
\end{abstract}

\section{Introduction}

Cirrhosis of the liver frequently leads to a state of chronic hypervolemic hyponatremia. The cause of the hyponatremia is related to a decrease in systemic vascular resistance [1], which is more prominent in the splanchnic circulation, and compensatory neurohormonal mechanisms that are activated due to the hemodynamic changes. The hyponatremia may be worsened in the setting of binge alcohol drinking which leads to the ingestion of large amounts of fluid containing little sodium [2]. Hyponatremia in cirrhosis can be a severe problem and has been shown to be an independent predictor of mortality in patients waiting for liver transplantation $[3,4]$. Here is presented a case of a patient with alcoholic cirrhosis who presents to the hospital with a serum sodium concentration of $105 \mathrm{meq} / \mathrm{L}$.

\section{Case presentation}

A 47-year-old Caucasian male was admitted with a three day history of shortness of breath, weakness, anorexia, and unsteady gait, including a recent fall. The patient

Correspondence: aj139@case.edu

Case Western Reserve University, School of Medicine, 10900 Euclid Ave, Cleveland, $\mathrm{OH}$ 44106, USA had a medical history significant for peptic ulcer disease, hypertension, and alcoholic cirrhosis. His family history was not significant. He reported smoking 2 packs per day and drinking 8-12 beers per day for the past 20 years. Over the previous 6 months, the patient had been unemployed and reported increased alcohol consumption. On physical exam, the patient was noted to have marked ascites with a prominent fluid wave and bulging flanks, bilateral pitting edema above the knees, and crackles as well as dullness to percussion in the left lower lobes. In addition, chest radiographs revealed a left lower lobe pneumonia. Significant laboratory studies included a WBC of $19.4 \times 10^{9} / \mathrm{L}$, AST of $107 \mathrm{U} / \mathrm{L}$, ALT of $66 \mathrm{U} / \mathrm{L}$, and serum sodium concentration of 105 $\mathrm{meq} / \mathrm{L}$. The patient was treated with IV furosemide (40 $\mathrm{mg} \times 1$ dose) and $3 \% \mathrm{NaCl}$ in addition to fluid restriction because of his symptomatic and profound hyponatremia. His serum sodium concentration increased to $120 \mathrm{meq} / \mathrm{L}$ over 48 hours and $130 \mathrm{meq} / \mathrm{L}$ over 96 hours with the use of $3 \% \mathrm{NaCl}$ and fluid restriction, and his weakness, anorexia, and unsteady gate improved. His pneumonia was treated with Vancomycin (1 g IV every $12 \mathrm{hrs}$ ) and Piperacillin/Tazobactam (3.375 mg IV every $6 \mathrm{hrs}$ ) which resulted in symptomatic and radiographic 
improvement. He was discharged from the hospital on oral spironolactone $(200 \mathrm{mg} /$ day $)$ and furosemide $(40$ $\mathrm{mg} /$ day) with recommendations for abstinence from alcohol, a low sodium diet, and fluid restriction.

\section{Discussion}

Chronic hyponatremia (defined as a serum sodium concentration below $130 \mathrm{meq} / \mathrm{L}$ ) occurs in up to 22 percent of people with cirrhosis [5], and is often asymptomatic if the serum sodium concentration is above $120 \mathrm{meq} / \mathrm{L}$ $[6,7]$. The percent of people with cirrhosis affected by chronic hyponatremia increases to 50 percent if a cutoff for serum sodium concentration of $135 \mathrm{meq} / \mathrm{L}$, the lower limit of normal, is used [5]. The frequency of such profound hyponatremia as seen at presentation in the patient in this case (serum sodium concentration of $105 \mathrm{meq} / \mathrm{L}$ ) is unclear; a population survey reported that the prevalence of patients with cirrhosis and serum sodium concentrations less than or equal to $120 \mathrm{meq} / \mathrm{L}$ is 1.2 percent [6].

The most common reason for chronic hyponatremia in cirrhosis is impairment in renal solute-free water secretion due to increased antidiuretic hormone secretion and decreased effective arterial volume $[5,8]$. The brain is able to compensate for the increased osmolar pressure (which leads to cerebral edema) in chronic hyponatremia by extruding intracellular osmolytes, such as potassium, glutamine and myoinositol, which can take 48 hours for full effect $[5,7,9]$. This adaptive mechanism explains why patients with chronic hyponatremia and serum sodium concentrations above 120 meq/L are often asymptomatic.

If there is an acute exacerbating condition however, such as infection or binge drinking as in this patient, the serum sodium concentration can rapidly drop to dangerously low levels for which the brain is unable to compensate acutely. Acute worsening of chronic hyponatremia may have various etiologic factors, including: generalized haemodynamic derangement with low peripheral resistance, reduced effective arterial volume, hypothalamic overproduction of antidiuretic hormone, elevated renin and angiotensin, hypotonic fluid ingestion and reduced glomerular filtration, all of which may lead to marked water retention $[5,7,8]$. The ingestion of large amounts of alcohol, a hypotonic fluid containing little sodium, may worsen the underlying chronic hyponatremia present in cirrhosis [2] and is believed to be a factor for the acute decompensation seen in this patient.

Common symptoms of chronic hyponatremia include fatigue, nausea, dizziness, lethargy, confusion, and gait disturbances $[10,11]$. In the setting of acute hyponatremia, or acute on chronic hyponatremia, seizures, coma, and respiratory arrest may occur [10]. It should be noted that the symptoms experienced by the patient presented in this report are likely multifactorial and due to both the profound hyponatremia and comorbid lobar pneumonia. Treatment of hyponatremia in patients with cirrhosis includes sodium and fluid restriction and continued treatments with spironolactone and loop diuretics. However, care must be taken when administering diuretics as they can exacerbate the reduction in tissue perfusion that occurs in cirrhosis, further impairing the ability to excrete free water [12]. Bolus infusions of $3 \%$ $\mathrm{NaCl}$ are reserved for patients with profound hyponatremia and severe symptoms [13]. Vasopressin receptor antagonists are newer therapies and their precise role in treating hypervolemic hyponatremia in patients with cirrhosis is not well-defined [5,7]. The serum sodium concentration in symptomatic hyponatremia should be corrected at a rate no more than $10 \mathrm{meq} / \mathrm{L}$ in the first 24 hours, $18 \mathrm{meq} / \mathrm{L}$ in the first 48 hours, and $20 \mathrm{meq} / \mathrm{L}$ in the first 72 hours to prevent iatrogenic brain injury and central pontine myelinolysis $[13,14]$. In patients with cirrhosis, it is important to recognize the symptoms of hyponatremia, identify and treat any exacerbating conditions early in their course, and correct the serum sodium concentration slowly with frequent monitoring.

\section{Consent}

Written informed consent was obtained from the patient for publication of this case report. A copy of the written consent is available for review by the Editor-in-Chief of this journal.

\section{Abbreviations}

ALT: alanine transaminase; AST: aspartate transaminase; IV: intravenous; $\mathrm{NaCl}$ : Sodium Chloride; WBC: white blood cell count.

\section{Competing interests}

The author declares that he has no competing interests.

Received: 18 March 2010 Accepted: 23 March 2010

Published: 23 March 2010

\section{References}

1. Groszmann RJ: Hyperdynamic circulation of liver disease 40 years later: Pathophysiology and clinical consequences. Hepatology 1994, 20:1359.

2. Hilden T, Svendsen TL: Electrolyte disturbances in beer drinkers. A specific "hypo-osmolality syndrome". Lancet 1975, 2:245.

3. Kim WR, Biggins SW, Kremers WK, Wiesner RH, Kamath PS, Benson JT, Edwards E, Therneau TM: Hyponatremia and mortality among patients on the liver-transplant waiting list. N Engl J Med 2008, 359(10):1018-1026.

4. Biggins SW, Rodriguez HJ, Bacchetti P, Bass NM, Roberts JP, Terrault NA: Serum sodium predicts mortality in patients listed for liver transplantation. Hepatology 2005, 41(1):32-39.

5. Ginès $P$, Guevara M: Hyponatremia in cirrhosis: pathogenesis, clinical significance, and management. Hepatology 2008, 48(3):1002-1010.

6. Angeli $\mathrm{P}$, Wong F, Watson H, Gines P: Hyponatremia in cirrhosis: Results of a patient population survey. Hepatology 2006, 44:1535.

7. Martín-Llahí M, Guevara M, Ginès P: Hyponatremia in cirrhosis: clinical features and management. Gastroenterol Clin Biol 2006, 30:1144-1151.

8. Moreau R: Hyponatremia in cirrhosis. Pathophysiology, prevalence, prognostic value, treatment. Acta Gastroenterol Belg 2008, 71(4):379-385. 
9. Sterns RH, Silver SM: Brain volume regulation in response to hypoosmolality and its correction. Am J Med 2006, 119(7 Suppl 1):S12-16.

10. Ellis SJ: Severe hyponatraemia: Complications and treatment. QJM 1995, 88:905.

11. Decaux G: Is asymptomatic hyponatremia really asymptomatic? Am J Med 2006, 1197(Suppl 1):S79-82.

12. Sherlock S, Senewiratne B, Scott A, Walker JG: Complications of diuretic therapy in hepatic cirrhosis. Lancet 1966, 1(7446):1049-1052.

13. Sterns RH, Nigwekar SU, Hix JK: The treatment of hyponatremia. Semin Nephrol 2009, 29(3):282-299.

14. Verbalis JG, Goldsmith SR, Greenberg A, Schrier RW, Sterns RH:

Hyponatremia treatment guidelines 2007: Expert panel recommendations. Am J Med 2007, 120:S1.

doi:10.1186/1757-1626-3-77

Cite this article as: Lindsay: Profound hyponatremia in cirrhosis: a case report. Cases Journal 2010 3:77.

Submit your next manuscript to BioMed Central and take full advantage of:

- Convenient online submission

- Thorough peer review

- No space constraints or color figure charges

- Immediate publication on acceptance

- Inclusion in PubMed, CAS, Scopus and Google Scholar

- Research which is freely available for redistribution

Submit your manuscript at www.biomedcentral.com/submit
C Biomed Central 